LA W RENCE LIVERM ORE N A TIONAL LABORATORY

First implosion experiments with cryogenic thermonuclear fuel on the National Ignition Facility

S. H. Glenzer

November 21, 2011

Plasma Physics and Controlled Fusion 
This document was prepared as an account of work sponsored by an agency of the United States government. Neither the United States government nor Lawrence Livermore National Security, LLC, nor any of their employees makes any warranty, expressed or implied, or assumes any legal liability or responsibility for the accuracy, completeness, or usefulness of any information, apparatus, product, or process disclosed, or represents that its use would not infringe privately owned rights. Reference herein to any specific commercial product, process, or service by trade name, trademark, manufacturer, or otherwise does not necessarily constitute or imply its endorsement, recommendation, or favoring by the United States government or Lawrence Livermore National Security, LLC. The views and opinions of authors expressed herein do not necessarily state or reflect those of the United States government or Lawrence Livermore National Security, LLC, and shall not be used for advertising or product endorsement purposes. 


\section{First implosion experiments with cryogenic thermonuclear fuel on the National Ignition Facility}

Siegfried H. Glenzer ${ }^{1}$, Brian K. Spears ${ }^{1}$, M. John Edwards ${ }^{1}$, Ethan T. Alger ${ }^{2}$, Richard L. Berger ${ }^{1}$, Darren L Bleuel ${ }^{1}$, David K. Bradley ${ }^{1}$, Joseph A. Caggiano ${ }^{1}$, Debra A. Callahan ${ }^{1}$, Carlos Castro $^{1}$, Daniel T. Casey ${ }^{3}$, Christine Choate ${ }^{1}$, Daniel S. Clark ${ }^{1}$, Charles J. Cerjan ${ }^{1}$, Gilbert W. Collins ${ }^{1}$, Eduard L. Dewald ${ }^{1}$, Jean-Michel G. Di Nicola ${ }^{1}$, Pascale Di Nicola ${ }^{1}$, Laurent Divol ${ }^{1}$, Shamasundar N. Dixit ${ }^{1}$, Tilo Döppner ${ }^{1}$, Rebecca Dylla-Spears ${ }^{1}$, Elizabeth G. Dzenitis ${ }^{1}$, James E. Fair ${ }^{1}$, Lars Johan Anders Frenje $^{3}$, M. Gatu Johnson ${ }^{3}$, E. Giraldez ${ }^{2}$, Vladimir Glebov ${ }^{5}$, Steven M. Glenn ${ }^{1}$, Steven W. Haan ${ }^{1}$, Bruce A. Hammel ${ }^{1}$, Stephen P. Hatchett $\mathrm{II}^{1}$, Christopher A. Haynam ${ }^{1}$, Robert F. Heeter $^{1}$, Glenn M. Heestand ${ }^{1}$, Hans W. Herrmann ${ }^{4}$, Damien G. Hicks ${ }^{1}$, Dean M. Holunga ${ }^{1}$, Jeffrey B. Horner ${ }^{1}$, Haibo Huang $^{1}$, Nobuhiko Izumi ${ }^{1}$, Ogden S. Jones ${ }^{1}$, Daniel H.

Kalantar $^{1}$, Joseph D. Kilkenny ${ }^{2}$, Robert K. Kirkwood ${ }^{1}$, John L. Kline $^{4}$, James P. Knauer ${ }^{5}$, Bernard Kozioziemski ${ }^{1}$, Andrea L. Kritcher $^{1}$, Jeremy J. Kroll ${ }^{1}$, George A. Kyrala ${ }^{4}$, Kai N. LaFortune $^{1}$, Otto L. Landen ${ }^{1}$, Douglas W. Larson ${ }^{1}$, Ramon J. Leeper ${ }^{6}$, Sebastien Le Pape ${ }^{1}$, John D. Lindl ${ }^{1}$, Tammy Ma ${ }^{1}$, Andrew J. Mackinnon ${ }^{1}$, Andrew G. MacPhee ${ }^{1}$, Evan Mapoles ${ }^{1}$, Patrick W. McKenty ${ }^{5}$, Nathan B. Meezan ${ }^{1}$, Pierre Michel ${ }^{1}$, Jose L. Milovich ${ }^{1}$, John D. Moody ${ }^{1}$, Alastair S Moore ${ }^{7}$, Mike Moran $^{1}$, Kari Ann Moreno ${ }^{2}$, David H. Munro ${ }^{1}$, Bryan R. Nathan ${ }^{1}$, Abbas Nikroo ${ }^{2}$, Richard E. Olson ${ }^{6}$, Charles D. Orth ${ }^{1}$, Arthur Pak ${ }^{1}$, Pravesh K. Patel ${ }^{1}$, Tom Parham ${ }^{1}$, Richard Petrasso $^{3}$, Joseph E. Ralph ${ }^{1}$, Hans Rinderknecht ${ }^{3}$, Sean P. Regan $^{5}$, Harry F. Robey ${ }^{1}$, J. Steven Ross ${ }^{1}$, Jay D. Salmonson ${ }^{1}$, Craig Sangster ${ }^{5}$, Jim Sater ${ }^{1}$, Marilyn B. Schneider ${ }^{1}$, F.H. Séguin $^{3}$, Michael J. Shaw ${ }^{1}$, Milton J. Shoup ${ }^{5}$, Paul T. Springer $^{1}$, Wolfgang Stoeff ${ }^{1}$, Larry J. Suter ${ }^{1}$, Cliff Avery Thomas $^{1}$, Richard P. J. Town ${ }^{1}$, Curtis Walters ${ }^{1}$, Stephen V. Weber $^{1}$, Paul J. Wegner ${ }^{1}$, Clay Widmayer ${ }^{1}$, Pamela K. Whitman ${ }^{1}$, Klaus Widmann ${ }^{1}$, Douglas C. Wilson ${ }^{4}$, Bruno M. Van Wonterghem ${ }^{1}$, Brian J. MacGowan ${ }^{1}$, L. Jeff Atherton ${ }^{1}$, 


\section{and Edward I. Moses ${ }^{1} \S$}

1. Lawrence Livermore National Laboratory, Livermore, California 94550, USA

2, General Atomics, San Diego, California 92121, USA

${ }^{3}$, Plasma Fusion and Science Center, Massachusetts Institute of Science and

Technology, Cambridge, Massachusetts 02139, USA

4, Los Alamos National Laboratory, Los Alamos, New Mexico 87545, USA

5 , Laboratory for Laser Energetics, University of Rochester, Rochester, New York 14623, USA

${ }^{6}$, Sandia National Laboratory, Sandia, New Mexico 87185, USA

7, Atomic Weapons Establishment, Aldermaston, RG7, UK

\section{Abstract.}

Non-burning thermonuclear fuel implosion experiments have been fielded on the National Ignition Facility to assess progress towards ignition by indirect drive inertial confinement fusion. These experiments use cryogenic fuel ice layers, consisting of mixtures of tritium and deuterium with large amounts of hydrogen to control the neutron yield and to allow fielding of an extensive suite of optical, $x$-ray, and nuclear diagnostics. The themonuclear fuel layer is contained in a spherical plastic capsule that is fielded in the centre of a cylindrical gold hohlraum. Heating the hohlraum with 1.3 mega joules of energy delivered by 192 laser beams produces a soft x-ray drive spectrum with a radiation temperature of $300 \mathrm{eV}$. The radiation field produces an ablation pressure of 100 mega bar which compresses the capsule to a spherical dense fuel shell that contains a hot plasma core $80 \mu \mathrm{m}$ in diameter. The implosion core is observed with $x$-ray imaging diagnostics that provide size, shape, the absolute $x$-ray emission along with bang time and hot plasma life time. Nuclear measurements provide the $14.1 \mathrm{MeV}$ neutron yield from fusion of deuterium and tritium nuclei along with down scattered neutrons at energies of $10-12 \mathrm{MeV}$ due to energy loss by scattering in the dense fuel that surrounds the central hot spot plasma. Neutron time of flight spectra allow the inference of the ion temperature while gamma ray measurements provide the duration of nuclear activity. The fusion yield from deuterium-tritiun reactions scales with ion temperature, which is in agreement with modeling over more than one order of magnitude to a neutron yield in excess of $10^{14}$ neutrons, indicating large confinement parameters on these first experiments. 


\section{Introduction}

Following commissioning of the National Ignition Facility (NIF) $[1,2]$ and demonstration of hohlraum symmetry $[3,4,5]$ with adequate soft $x$-ray drive $[6,7,8]$ several new experimental platforms have been fielded to tune the performance of indirectly driven inertial confinement fusion capsule implosions [9, 10]. These tuning experiments [11] measure and optimize four general tuning parameters including symmetry during the foot and the peak of the laser drive, shock timing; implosion velocity, and hydrodynamic mix. The goal of the tuning campaigns is to field a fusion experiment that uses equimolar deuterium-tritium (DT) fill and that has a high probability for achieving ignition and burn $[12,13]$.

Of central importance to the progress towards ignition with each tuning step is the assessment of hot spot formation and thermonuclear fuel assembly. These processes are characterized by the neutron yield from primary deuterium-tritium reactions in the central hot plasma, $D+T={ }^{4} \mathrm{He}(3.5 \mathrm{MeV})+n(14.1 \mathrm{MeV})$, and the ratio of down scattered to primary neutrons, $N(10-12 \mathrm{MeV}) / N(13-15 \mathrm{MeV})$, quantifying neutrons that have lost energy by scattering processes in the dense fuel plasma that surrounds the central hot plasma. These measured quantities are combined into an experimental ignition threshold factor $[14,15]$. Radiation-hydrodynamic simulations and analytical modeling have shown that this performance metric can be tied to the Lawson confinement criterion [16] for inertial confinement fusion $[17,18]$ that measures the proximity of a fusion experiment towards the regime of sufficient density or pressure, confinement time, and temperature required for ignition. For this purpose, cryogenic layered capsule implosion experiments have been designed to emulate ignition conditions in a non alpha particle self heating, non-burning implosion, thus allowing a large suite of diagnostics to be fielded in a controlled neutron flux enviromment [19].

The implosion experiments employ a 2.26 mm-diameter fusion capsule with approximately $0.17 \mathrm{mg}$ of nuclear fuel. The fuel is prepared cryogenically into a solid ice layer of hydrogen isotopes on the inside of a low-Z (plastic) ablator. The capsule is placed in the centre of a centimetre-scale hohlraum that is heated by up to 1.3 mega joules of laser energy, generating ablation pressures in excess of $100 \mathrm{MBar}$. The rocket-like acceleration of the shell in response to the ablation pressure compresses the shell toward the centre with the goal to produce fuel densities of $1000 \mathrm{~g} / \mathrm{cm}^{3}$. This high density shell of fuel surrounds a hot spot which, for ignition, will reach temperatures in excess of $10 \mathrm{keV}$ from a combination of PdV work and alpha particle deposition. At this point, a nuclear burn wave is launched igniting the surrounding dense fuel, sustained by alpha deposition and electron conduction without an external energy source $[9,10,20,21]$. Burning approximately $1 / 3$ of the DT-fuel will result into $6.5 \times 10^{18}$ fusion neutrons with a total neutron yield of $15 \mathrm{MJ}$.

In the present study, the fuel has been diluted using Tritium-Hydrogen-Deuterium (THD) mixtures; specifically $6 \%$ deuterium to control nuclear yield, and $72 \%$ tritium with $22 \%$ hydrogen to provide the same fuel mass as DT implosions. The fuel has 
Figure 1. Schematic of an ignition scale holdraum is shown along with a fusion capsule for cryogenic layered implosions. The hohlraum is heated with 192 laser beams in four cones at angles of $23.5^{\circ}, 30^{\circ}, 44.5^{\circ}$, and $50^{\circ}$ to the hohlraum axis. The fusion capsule uses five plastic layers of various thickness, three of which are doped with germanium with varying concentration to absorb high energy x-rays from the gold hohlraum and to taylor the density gradient at the ablator-fuel interface. On the inside of the ablator, a. $68 \mu \mathrm{m}$ thick ice layer is produced that contains most of the muclear fuel.

been fielded in a $68 \mu \mathrm{m}$ thick layer. A fuel layer with characteristics that meets the specifications for ignition has been demonstrated, i.e., adequate sphericity with a total groove area from local defects of less than $200 \mu \mathrm{m}^{2}$ and an averaged root mean square value of less than $0.7 \mu \mathrm{m}$. The laser driven hohraum radiation field compresses the capsule symmetrically to a sphere with a central hot-spot diameter of $80 \mu \mathrm{m}$. In addition, the experiments have successfully demonstrated the control of the implosion shape using ignition grade cryogenic fuel layers [22], laser power balance and pulse shaping [2], and plasma optics gratings $[3,4,23]$. For a burn averaged ion temperature of $T_{i}=3.5 \mathrm{keV}$, these implosions provide $10^{14}$ neutrons at $14.1 \mathrm{MeV}$ energy and an accurate $( \pm 10 \%)$ measurement of the down-scattered ratio, i.e., the neutron fraction that lost energy in the dense fuel through scattering processes. These first experiments show high values for the Lawson fusion parameter and demonstrate thermonuclear fuel implosion experiments that provide adequate implosion performance data on hot-spot formation and nuclear fuel assembly needed for determining progress towards ignition.

The paper is organized as follows. Section 2 describes the hohlraum and capsule target together with fuel layer capabilities on NIF. An example of a groove analysis for a cryogenic fuel layer used for shot selection is also provided. Section 3 describes the laser drive and soft $x$-ray production in the hohlraum. The resulting capsule implosion symmetry and core shape is shown. Section 4 presents nuclear data from cryogenic layered implosion experiments indicating accurate measurements of hot spot formation

and nuclear fuel assembly. This section also provides a brief performance assessment analysis in the form of an experimental ignition threshold factor and estimates of the Lawson confinement parameter that show high values for these initial experiments. Section 5 presents the conclusions.

\section{Cryogenic thermonuclear fuel targets}

\subsection{Hohlraum and capsule}

Figure (1) shows a schematic of the hohlraum, capsule, and nuclear fuel ice layers employed in these experiments. For a fuel layer with $6 \% \mathrm{D}$, the targets are prepared cryogenically to achieve a nominal shot temperature of $17.4 \mathrm{~K}$, i.e., $\Delta T=-1.5 \mathrm{~K}$ below the triple point of the phases of THD. This temperature is reached a few seconds before the system shot by lowering the target temperature over a period of a 30-second long 
Figure 2. (a) Picture of cryogenic ignition target before fully enclosed by the shroud. (b) The storm window is seen on the top laser entrance hole (LEH) of the cylindrical hohlraum target. On the side of the hohlraum, a cutout can be identified which is covered with a $10 \mathrm{~mm}$ thick Au coating and that allows characterization of the ice fuel layer during the layering process.

quench. Active (cascade) temperature control during this time assures that the required shot temperature is reached with an uncertainty smaller than $2 \mathrm{mK}$.

The quench is implemented to provide the desired vapor pressure inside the fusion capsule with a gas density of $0.3 \mathrm{mg}$ for DT [24]. This procedure is required because smooth ice layer surfaces can presently be made only close to the triple point [22]. Independent tests have show that the layer quality is stable from the time of final layer characterization to the laser shot. At cryogenic temperatures the gold hohlraums are $1 \mathrm{~cm}$ long with a diameter of $5.44 \mathrm{~mm}$ and filled with helium gas at a pressure of 260 torr resulting in densities of $0.96 \mathrm{mg} \mathrm{cm}^{-3}$.

Figure (2) shows two views of an ignition hohlraum target mounted on the cryogenic target positioner before being enclosed by a shroud. The shroud protects the target from chamber thermal radiation during the cryogenic layering process as well as from gaseous impurities that condenses on cold surfaces. The shroud opens 8 seconds before the laser beams are fired; the opening results in an increase in temperature due to exposure to thermal radiation of about $400 \mathrm{mK}$, which is compensated for so that the final temperature is reached within less than 3 seconds. Protection of the target from ice condensates during layering and during the final exposure to the target chamber atmosphere is provided by the laser entrance hole (LEH) storm windows. These consist of thin plastic foils coated with $40 \mathrm{~mm}$ carbon film to absorb $100 \mathrm{~K}$ and $300 \mathrm{~K}$ thermal radiation which will keep the LEH ice free. This important feature has enabled proper laser beam propagation during the low power foot of the laser pulse at a typical chamber pressure of $10^{-5}$ torr and a total exposure of $2.3 \times 10^{-4}$ torr hours. Thus, the first shock launched during the picket of an ignition laser pulse is adequately delivered [25]. In this study, we show that when storm windows are used, there is an approximate agreement in the observed implosion symmetry of a layered THD implosions and high pressure gas-filled plastic shells, i.e., symcap implosions.

\subsection{Thermonuclear fuel layer}

Figure 3 shows characterization of the fuel distribution inside the capsule measured along 3 lines of sight with $9 \mathrm{keV}$ x-ray point projection radiography using a tungsten L-emission source. An axial view (Fig, 3(a)) is provided through the laser entrance holes and 2 orthogonal views (Fig. 3(b) and (c)) are obtained in the equatorial plane through cut outs in the hohlraum cylinder walls. These so-called starburst windows can be identified underneath a $10 \mu \mathrm{m}$ gold coating in Fig. 2 on the side of the hohlraum. 
Figure 3. X-ray characterization of THD ice layers at a temperature of $18.4 \mathrm{~K}$ through the LEH and the star burst cut outs. $(a-c)$ Fusion capsule is shown from three lines of sight. The dark ring is due to absorption of $x$-rays in the Ge-doped plastic shell and a $68 \mu \mathrm{m}$-thick THD ice layer can be seen on the inside of the shell. Also shown (d) is the capsule with THD fill at the triple point temperature of $18.9 \mathrm{~K}$. The power spectral density versus node number is shown in (e). A summary of the layer groove characterization is provided in terms of the maximum length and the $K$-values for the first four THD shots (f).

Ice layer preparation is performed within a shroud that consists of two enclosures; the outer one at $300 \mathrm{~K}$ and the imner one cooled to $100 \mathrm{~K}$. The shroud has 4 Al-coated and 12 Au-coated windows to allow x-ray characterization and subsequent alignment of the target at target chamber centre. These alignment windows are covered with a total of $25 \mathrm{~mm}$ thick gold foils to prevent thermal radiation from heating the target. The capsule is first filled at a temperature of $500 \mathrm{mK}$ below the triple point of the THD fill so that the fuel is in a slightly supercooled liquid state. Filling will continue until the height of the meniscus as observed in the side windows approximately indicates the desired fuel inventory, cf. Fig. 3(d). The target is then cooled rapidly by $1-2 \mathrm{~K}$ to plug the fill tube and to obtain the total capsule fuel.

The resulting ice is polycrystalline with many crystals. A subsequent slow warming period of the capsule, at a rate of $1 \mathrm{mK} / \mathrm{min}$ to $18.9 \mathrm{~K}( \pm 0.03 \mathrm{~K})$ for THD or $19.8 \mathrm{~K}$ $( \pm 0.03 \mathrm{~K})$ for $\mathrm{DT}$, will melt the solid back into the fill tube. The ice will melt and accumulate at the bottom of the capsule; the meniscus height will increase until the maximum of the triple point range has been reached; for THD this range may approach $100 \mathrm{mK}$ and for DT the range is $30 \mathrm{mK}$. With frozen ice in the fill tube isolating the capsule from the reservoir, a measurement of the meniscus height of $258 \mu \mathrm{m}( \pm 4.5 \mu \mathrm{m})$ determines the final fuel inventory. Figure 3 (d) shows the fill that provides an ice layer thickness of $68 \mu \mathrm{m} \pm 1.5 \mu \mathrm{m}$.

A subsequent drop of the capsule temperature by $45 \mathrm{mK}$ is performed so that the fill tube ice provides a seed for growing the capsule ice layer with the correct orientation [22]. The seed is initially in an unstable fcc ice phase which converts to hcp crystals. Layering is started at a temperature of $100 \mathrm{mK}$ below the triple point and slowly cooled to about $400 \mathrm{mK}$ below the triple point over a period of 14 to 18 hours. This method relies on the radioactive self heating from beta decay in the condensed THD, which enables redistribution of the solid along the isotherms in the capsule and is known as beta layering $[26,27,28]$. The target is then shot within 3 days to prevent helium build up from beta decay of tritium.

\subsection{Fuel layer characterization}

Figure 3(e) shows an example of the results from a mode analysis for a layered THD experiment. The Power Spectral Density $(P S D)$ provides a measurement of the 
deviation from a spherical shape along the three lines of sight for all modes starting from $m=2$ to $m=150$. Also shown is the NIF specification that is derived from radiationhydrodynamic simulations $[29,30]$ and that estimates the maximum deviation allowed for an ignition experiment. This measurement of background roughness of ice layers is then used to calculate the effect on the observed neutron yield. For this purpose, we normalize the measured $P S D$ to the specification and average over the four ranges of modes with different slopes,

$$
n f a=\sqrt{\sum_{j=1}^{4} n f_{j}^{2}}
$$

with

$$
\begin{aligned}
& n f_{1}=\sqrt{\frac{1}{6} \sum_{m=1}^{6} \frac{P S D_{m}}{P S D_{s p e c}}}, n f_{2}=\sqrt{\frac{1}{6} \sum_{m=7}^{12} \frac{P S D_{m}}{P S D_{\text {spec }}}}, \\
& n f_{3}=\sqrt{\frac{1}{13} \sum_{m=13}^{25} \frac{P S D_{m}}{P S D_{\text {spec }}}}, n f_{4}=\sqrt{\frac{1}{125} \sum_{m=26}^{150} \frac{P S D_{m}}{P S D_{\text {spec }}}} .
\end{aligned}
$$

This mode analysis is combined with an estimate for the impact of isolated defects on the neutron yield of tuned implosions. The total effect of grooves on hot spot rms takes into account the sum over all defects of area $A$ and length $L$,

$$
K=\sqrt{\frac{1}{V_{\text {fuel }}} \sum_{j=1}^{n} A_{j}^{2} L_{j}}
$$

where we require

$$
A \leq 250 \mu \mathrm{m}^{2}
$$

to avoid a groove from breaking through the DT layer during the implosion.

Figure 3(f) shows the largest groove area and the effective $K$-values for four implosion experiments. This data show one ignition grade layer with $K<0.7$ and three marginal layers for tuning experiments, $0.7<K<1.5$. The effect of non-perfect layers on the neutron yield is estimated

$$
y f=1.3-\frac{3}{\sqrt{2}}\left(4.9 \times 10^{-3} n f a^{2}+1 \times 10^{-1} K^{2}\right)^{\frac{1}{2}} .
$$

We find a yield factor of $y f=1$ for the ignition grade layer with $A<100 \mathrm{~m}^{2}$, $K<0.5 \mu \mathrm{m}$; for the remaining three layers this values reduces to yf $=0.5 \pm 0.1$. The calculated neutron yield performance will be lowered by including the effects of ice roughness on the capsule. The yield factor will likely be improved and approach a value of $y f \simeq 1$ in future layered experiments as tests have shown improved layer quality with increasing deuterium fraction. 


\section{Capsule Implosion Experiments}

\subsection{Laser Drive}

The hohlraums are heated with 192 frequency-tripled ( $3 \omega$ ) laser beams at a wavelength of $351 \mathrm{~mm}$ through two laser entrance holes (LEHs) of $3.1 \mathrm{~mm}$ diameter on either end, cf. Fig. 1. The beams are arranged in four cones entering through each LEH; the inner two cones being at angles of $23.5^{\circ}$ and $30^{\circ}$ and the outer two cones being at $44.5^{\circ}$ and $50^{\circ}$ to the vertical axis.

Figure 4(a) shows examples of the total $3 \omega$ laser powers together with the powers in the inner and outer cones of beams. In these experiments, the laser beams delivered up to 400 TW peak power in a 21-ns long shaped pulse, providing a total energy of $(1.3 \pm 0.03)$ MJ energy. We employ smoothed beams $[2,31,32]$ with polarization rotation $[33,34]$, smoothing by spectral dispersion with a laser bandwidth of $60 \mathrm{GHz}$ and a $17 \mathrm{GHz}$ frequency oscillator. In addition, continuous phase plates are employed that give elliptical vacuum spot sizes $[35,36]$ major radius, $a$, and minor radius, $b b$ of the ellipse. On the $23.5^{\circ}$ beams we use $a=0.8817 \mathrm{~mm}, b=0.6313 \mathrm{~mm}$, on the $30^{\circ}$ beams we use $a=0.824 \mathrm{~mm}, b=0.59 \mathrm{~mm}$, on the $44.5^{\circ}$ beams we use $a=0.6345 \mathrm{~mm}$, $b=0.6313 \mathrm{~mm}$, and on the $50^{\circ}$ beams we use $a=0.593 \mathrm{~mm}, b=0.343 \mathrm{~mm}$. These spots result in quad vacumm peak intensities of $I_{23.5}=4.8 \times 10^{14} \mathrm{~W} \mathrm{~cm}^{-2}, I_{30}=5.5 \times 10^{14} \mathrm{~W}$ $\mathrm{cm}^{-2}, I_{44.5}=1.2 \times 10^{15} \mathrm{~W} \mathrm{~cm}^{-2}$, and $I_{50}=1.3 \times 10^{1.5} \mathrm{~W} \mathrm{~cm}^{-2}$ for the $400 \mathrm{TW}$ laser drive.

For the NIF hohlraum and laser configuration, a total of 64 inner beams (16 quads) are focussed into a ring in the equatorial plane of the hohlraum, 8 quads from the top hemisphere in the $23.5^{\circ}$ and $30^{\circ}$ cones and 8 quads from the bottom hemisphere. In addition, on either side of the capsule, 16 outer quads irradiate the hohlraum wall in a ring-like pattern about half way between the equatorial plane and the laser entrance hole plane, cf. Fig. 1. Thus, we expect a symmetric capsule implosion when the beam power in the three rings of beams is balanced such that the inner beam power is approximately $1 / 3$ of the total power. At the peak of the drive, this choice for the laser cone fractions was adopted while the early picket cone fraction has been adjusted between the $1 \mathrm{MJ}$ and 1.3 MJ implosions based on improved symmetry information from reemit experiments [37], cf. Fig. 4(b). In the present study, calculations have determined the cone fraction during the remaining parts of the laser pulse. In future tuning experiments, symmetry will be tuned throughout the pulse using velocity interferometer measurements on the shock waves at two orthogonal angles $[38,39,40]$.

At these energies and powers, the hohlraum absorbs $80-90 \%$ of the incident energy with the dominating loss mechanism being due to Stimulated Raman Scattering (SRS) $[41,42]$ on the inner cones of beams as measured with a full aperture backscatter diagnostics and near backscatter imagers [43]. For example, the $1.3 \mathrm{MJ}$ driven hohlraum shows a total of $14.2 \mathrm{~kJ}[ \pm 4.3 \mathrm{~kJ}]$ on a $23.5^{\circ}$ quad of beams and $12.7 \mathrm{~kJ}[ \pm 3.9 \mathrm{~kJ}]$ on a $30^{\circ}$ quad of beams. Scattering losses on the outer beams are negligible, a total of $210 \mathrm{~J}[\mathrm{H} / \mathrm{-}$ $40 \mathrm{~J}$ ] of Stimulated Brillouin Scattering has been measured on a $50^{\circ}$ quad of beams. With 
Figure 4. (a) Measured incident and requested laser powers of hohlraums driven by total energies of $1 \mathrm{MJ}$ (blue) and $1.3 \mathrm{MJ}$ (red) for shots N100929 and N110212, respectively. The total laser powers are shown together with power on the outer and imner cones of beams. While the 1 MJ laser pulse reaches a peak power of $300 \mathrm{TW}$, the $1.3 \mathrm{MJ}$ drive rises to $400 \mathrm{TW}$ with a 600 ps faster rise. (b) The laser cone fractions as a function of time are shown; the $1.3 \mathrm{MJ}$ laser drive employs a lower equatorial drive during the early picket and a slightly higher equatorial drive at peak power.

8 quads at $23.5^{\circ}$ and 8 quads at $30^{\circ}$ relative to the hohlraum axis, these measurements result in an estimated coupling of $1-[222 \mathrm{~kJ} / 1300 \mathrm{~kJ}]=0.83 \pm 0.04$ providing $1.08 \mathrm{MJ}$ of absorbed laser energy to achieve the required radiation temperature and to drive the implosion.

SRS can effect the implosion performance in two important ways. First, damping of the SRS driven electron plasma waves produces hot electrons [44, 45]. Measurements with an $x$-ray filter fluorescer [46] indicate about $500 \mathrm{~J}$ of electrons with energies $>170 \mathrm{keV}$ that have the potential to generate capsule pre-heat. The measured hot electron numbers are about a factor of 2 below current tolerated upper limits for ignition $[7,9]$. Direct hard x-ray imaging of the capsule implosion has recently shown that preheat of the fuel is consistent with the low estimate by FFLEX [47]. Secondly, SRS losses affect capsule implosion symmetry.

In this study, the SRS scattering losses on the inner beams have been compensated for and a symmetric radiation drive on the capsule has been achieved using laser wavelengths of $1053.4 \mathrm{~mm}$ on the $23.5^{\circ}$ and $30^{\circ}$ cones of beams and $1052.8 \mathrm{~mm}$ on the $44.5^{\circ}$ and $50^{\circ}$ cones of beams. The wavelength shift enhances power transfer from the outer cones of laser beams to the inner cones by laser scattering on self-generated plasma optics gratings in the LEH area $[3,4,23,48,49]$. Power transfer increases the inner beam power by a factor of $1.5-2$ while allowing all beams to be operated at maximum power producing the required symmetric soft $\mathrm{x}$-ray drive on the capsule (Sec.IIIc).

\subsection{Hohlraum Temperature}

Figure 5 shows experimental and calculated hohlraum radiant intensity as function of time. The measurements of the x-ray power, $P$, in the energy range of $0<$ $E_{X-\text { ray }}<20 \mathrm{keV}$ out of the laser entrance hole $(\mathrm{LEH})$, have been performed with the absolutely calibrated broadband $x$-ray spectrometer Dante $[6,50,51]$. We find that both the temporal dependence and peak values are in excellent agreement with radiation-hydrodynamic modeling using the code LASNEX [8, 29]. Also shown as insets are the voltage traces from Dante channel 18, which has been set up to observe Ar K-shell x-rays at $2 \mathrm{keV}$ along with simulated total soft $\mathrm{x}$-ray Dante images at $2 \mathrm{~ns}$ into the pulse.

From the measured radiant intensity, the temperature can be inferred via $d P / d \Omega=$ $A_{L E H}(t) \phi(t) \cos \theta \sigma T_{R A D}^{4} / \pi$. Here, $\sigma$ is the Stefan-Boltzmam constant and $\theta$ is the 
Figure 5. (a) Measured and calculated (a) Dante hohlraum radiant intensity as function of time for $1 \mathrm{MJ} N 100929$ shot and $1.3 \mathrm{MJ}$ N110212 shot. The inset in (a) shows $2 \mathrm{keV}$ Dante chamnel 18 and calculated Dante images during the first 2 ns. (b) Hohlraum peak radiation temperatures are showlz versus absorbed laser energy.

view angle of Dante towards the hohlraum axis. The dynamically varying source area, $A_{L E H}(t)$ is estimated from the $3-5 \mathrm{keV}$ x-ray images [52] of the LEH measured with the Static X-ray Imager, SXI, c.f. Fig. (1). These measurements show a reduction of the LEH diameter to $83 \%$ of the initial value. $\phi$ is the view factor that relates the Dante measured drive with the radiation temperature seen by the capsule.

Recent implementation of a time-integrating soft x-ray imager of the LEH at $900 \mathrm{eV}$ has provided new measurements of the LEH aperture, indicating that about $10 \%$ of the Dante measured radiant intensity is due to emission from the ablated Au plasma that reduces the LEH clear aperture [53]. Assuming $90 \%$ of the measured flux from the hohlraum interior, applying the measured LEH aperture, and adding a small view-factor correction results in a $10 \mathrm{eV}$ corrections for these experiments.

The internal hohlraum radiation temperatures are modeled by balancing the absorbed laser power with the x-ray power radiated into the wall, $P_{W}$, absorbed by the capsule, $P_{C A P}$, and the power that escapes through the LEH, $P_{L E H}$,

$$
\begin{aligned}
& \eta_{\mathrm{CE}}\left(P_{\mathrm{L}}-P_{\text {Backscatter }}\right) \\
= & P_{\mathrm{W}}+P_{\mathrm{LEH}}+P_{\mathrm{CAP}} \\
= & \sigma T_{\mathrm{RAD}}^{4}\left[\left(1-\alpha_{\mathrm{W}}\right) A_{\mathrm{W}}+A_{\mathrm{LLHH}}+\left(1-\alpha_{\mathrm{CAP}}\right) A_{\mathrm{CAP}}\right] .
\end{aligned}
$$

With $\eta_{\text {ce }}$ being the x-ray conversion efficiency from laser power to soft $x$-rays [54]; $\alpha_{W}$ and $\alpha_{\mathrm{CAp}}$ are the $\mathrm{x}$-ray albedo of the hohlraum wall and the capsule, respectively. The albedo is defined as the ratio of re-emitted to incident $x$-rays. The hohlraum wall area, laser entrance hole area, and capsule surface area are denoted by $A_{W}, A_{\mathrm{LEH}}$ and $A_{\mathrm{CAP}}$, respectively. Assuming a conversion efficiency of $\eta_{C E}=0.9$ at peak laser power, Eq. (6) indicates peak radiation temperatures of $260 \mathrm{eV}<T_{R A D}<305 \mathrm{eV}$ for experiments with varying peak laser power.

Figure 5(b) shows the experimental peak radiation temperatures for various hohlraum experiments as function of the absorbed energy along with results from radiation hydrodynamic modeling with the code LASNEX that uses the detailed configuration accounting model for x-ray opacities [8]. Generally, we observe good agreement between data and modeling; in particular, at ignition scale we have achieved a hohlraum drive of $300 \mathrm{eV}$ at $1.1 \mathrm{MJ}$ absorbed energy. Also shown in Fig. 5 are the Marshak scaling results $[55,56,57]$ of Eq. (6) assuming a conversion efficiency of $\eta_{c e}=0.9$ and the albedo calculated according to [58]. The latter increases according to the data and integrated modeling and provides a good match to the experimental data at both hohlraum scales.

The uncertainty of the measured radiant intensity is $7 \%$, which results in an 
error bar of $\pm 5 \mathrm{eV}$ for the measured peak radiation temperature. In this study, the analysis does not include the very soft chamels of Dante that are contaminated with signal from unconverted laser light irradiating the target aluminum-plated silicon arms; compared to using all channels we find that this effect reduces the peak intensity by approximately $100 \mathrm{GW} / \mathrm{sr}$. An additional $105 \mathrm{GW} / \mathrm{sr}$ reduction of the peak values has been assumed as the contribution of unconverted light to the remainder of the chamnels. These corrections are less than $2 \%$ of the peak values and do no change the error estimate significantly. However, during the early low intensity foot of the drive these corrections are proportionally much larger, resulting in an estimate for the error bar of $\pm 10 \mathrm{eV}$. Another source of uncertainty is due to the view factor, i.e., the estimated drive of the capsule. In this study, the emission of the LEH ablated plasma has been subtracted when estimating the internal radiation temperature; in future studies, to improve accuracy, additional view factor corrections may be needed due to the size of the gold plasma that is ablated from the hohlraum walls.

For seven experiments with 1 to 1.08-MJ laser energy delivered to the hohlraum, the hohlraum absorbs $870 \pm 30 \mathrm{~kJ}$ and the radiation temperature varies from 281 to 288 $\mathrm{eV}$ with an absolute error bar of $5 \mathrm{eV}$. This data indicate a reproducible temperature with a standard deviation of approximately $3 \mathrm{eV}$ in temperature and $4 \%$ for the radiant intensity. These results meet the requirements for the ignition point design.

In addition at 1.3 MJ energy, symmetric implosions have been achieved. For layered THD implosions, this observation is correlated with adequate drive in the foot during the first $12 \mathrm{~ns}$ of the experiment. The inset in Fig. 5(a) shows that during the first 3 ns the $2 \mathrm{keV}$ Dante signal is appreciably larger for the $1 \mathrm{MJ}, 1.1 \mathrm{TW} / \mathrm{sr}$ layered THD implosion shot N100929 than for the $1.3 \mathrm{MJ}, 1.4 \mathrm{TW} / \mathrm{sr}$ layered THD implosion shot N110212. This difference is attributed to condensates on the LEH windows for the early 1 MJ experiment. Subsequent 1.3 MJ THD implosions used storm windows, resulting in a much smaller early time $2 \mathrm{keV}$ Dante signal indicating the lack of Ar emission from condensates and a total signal level consistent with expectations. This is illustrated in the Dante drive as calculated with 2-dimensional radiation-hyrodynamic simulations [30] that show bright early time emission when the laser beams burn through $1 \mu \mathrm{m}$ thick condensate. Without condensates, however, a much less intense signal from the hohlraum walls is predicted for the first $2 \mathrm{~ns}$ of the experiment than compared with condensates.

\subsection{Implosion Symmetry}

At peak compression, the implosion symmetry is inferred from high-resolution $(10 \mu \mathrm{m})$ temporally resolved ( $40 \mathrm{ps}$ ) imaging measurements of the $\mathrm{x}$-ray cmission from the central hot-spot plasma. These measurements can be quantified $[59,60,61]$ by decomposing the soft $x$-ray flux asymmetry at the capsule into Legendre polynomials, $P_{n}$. Odd orders $(n=1,3, \ldots)$ are approximately zero due to the up-down illumination symmetry and loworder even modes $(n=2,4, \ldots)$ are the most important asymmetries. Higher order drive 
Figure 6. Comparison of the $x$-ray emission images at 9-keV energy from (a) a layered THD implosion, shot N110212, and (b) high-pressure gas-filled "symcap" implosion, shot N110214. Both experiments use a $1.3 \mathrm{MJ}$ laser drive and identical laser cone fractions and wavelengths. Data are shown shortly before peak x-ray emission which occurs at $t=21.3 \mathrm{nst} 0.1 \mathrm{~ns}$ in both cases. The hohlram axis of symmetry is vertical.

variations are negligibly small and smoothed by the hohlraum radiation enviromment.

Figure 6 shows the x-ray emission from the 1.3 MJ THD implosion and a comparison symcap implosion with the same hohlraum drive conditions. While THD capsule use $68 \mu \mathrm{m}$ thick THD ice layers that contain the nuclear fuel, the symcap implosions employ a $32 \mu \mathrm{m}$-thick plastic layer instead of a $5 \mu \mathrm{m}$-thick layer on the inside of the Ge-doped layers; the additional mass simulates the fuel payload. The symcap capsule is shot at cryogenic temperatures of $24 \mathrm{~K}$ and uses a high pressure $30 \% \mathrm{D}_{2}, 70 \%{ }^{3} \mathrm{He}$ fill at 6.32 $\mathrm{mg} / \mathrm{cm}^{3}$. The symcap implosions have been routinely used for shape measurements $[3,7,8,62]$ while the THD experiments provide additional areal density and hot spot formation data in preparation for DT fills [19].

For the THD implosion in Fig. 6a, the x-ray peak emission (bangtime) is at $t=21.35 \pm 0.03 \mathrm{~ns}$, the burn width is $180 \pm 40 \mathrm{ps}$ with the following Legendre coefficients: $P_{0}=42 \mu \mathrm{m}, P_{2} / P_{0}=0.13, P_{4} / P_{0}=0.02, P_{6} / P_{0}=-0.06$. The orthogonal view also indicates a fairly symmetric implosion with $M_{0}=39 \mu \mathrm{m}, M_{2} / M_{0}=0.07$, and $M_{4} / M_{0}=0.07$, and similar values for bangtime and burn width of $t=21.39 \pm 0.03 \mathrm{~ns}$ and $210 \pm 40 \mathrm{ps}$, respectively. These values compare well with the symcap implosion where the $\mathrm{x}$-ray peak emission is at $t=21.35 \pm 0.03 \mathrm{~ns}$, the burn width is $186 \pm 40 \mathrm{ps}$, and the following Legendre coefficients: $P_{0}=62 \mu \mathrm{m}, P_{2} / P_{0}=0.14, P_{4} / P_{0}=0.07$, $P_{6} / P_{0}=-0.06$ with $M_{0}=55 \mu \mathrm{m}$ and $M_{4} / M_{0}=0.042$.

We have achieved symmetric implosions and adequate equatorial $x$-ray drive without changing the initial inner and outer cone laser powers. This tuning mechanism takes advantage of the multiple laser beam interactions with the plasma in the LEH area where all the beams cross. Transferring power into the inner beams allows us to compensate for SRS losses of the inner beams. Current imner beam SRS energy losses of order $10-15 \%$ of the total energy delivered into the hohlraum are expected to affect the local soft $\mathrm{x}$-ray production and drive symmetry during the peak of the laser drive.

The crossing lasers in the LEH produce spatial intensity modulations. These intensity modulations further drive plasma electron density modulations due to the ponderomotive force. If these modulations move with the plasma sound speed $C_{S}$ then modulations and laser scattering will grow to large levels and efficient energy transfer between beams will occur. In the rest frame, the power transfer rate, $Q$, is determined by

$$
Q \sim\left[\left(\omega_{1}-\omega_{2}\right)-k_{A}\left(C_{S}-V_{p}\right)+i \nu\right]^{-2} .
$$

In Eq. $7, V_{p}$ is the plasma flow velocity and $\nu$ is the Landau damping rate for acoustic fluctuations. The frequency de-tuning between pairs of beams is denoted as $\omega_{1}-\omega_{2}$. 
This factor allows us to control the energy transfer between cones of beams in integrated hohlraum experiments, and can be set to transfer power into either cone of beams. Proper choice of the laser wavelength difference of $\delta \lambda=0.6 \mathrm{~mm}$ (at the fundamental glass laser wavelength) for data in Fig. 6 have provided the desired x-ray drive symmetry.

\section{Nuclear Performance of layered THD Implosions}

\subsection{Hot Spot Formation}

The high temperatures of ICF implosions produce brief flashes of DT or DD neutrons with thermally broadened spectral peaks. The neutron flashes spread in time as they travel to intercept Neutron Time Of Flight (NTOF) detectors, producing a signal pulse that provides yield (from the pulse integral), the spectral width (or burn temperature) from the pulse width, and neutron "bangtime" from the pulse centre time. Bangtime numbers indicate the time of maximum neutron yield rate, which is generally within 100 ps of maximum $x$-ray and gamma ray emission. Scintillator/photodetector combinations provide high sensitivity ( $>10 \%$ interaction, with $\simeq 2$ ns response time, while solid state thin CVD diamond detectors (typically $<1 \mathrm{~mm}$ ) provide fast time response ( $<1 \%$ interaction, $\simeq 1$ ns response time). Here, interaction is the probability that a neutron passing through the detector will interact with it. Neutrons passing through thick scintillators have a higher probablity to interact, which is part of the reason for its higher sensitivity. As a general rule, NTOF detectors closest to the source record the most accurate bangtimes and yields; while the increased temporal spreading in detectors further from the source results in more accurate burn temperature measurements.

Figure 7 shows normalized NTOF data from the NTOF-20-E detector for a $1 \mathrm{MJ}$ and a $1.3 \mathrm{MJ}$ THD implosion. This detector is at a distance of about 22 metre from target chamber centre and in the equatorial plane at $\theta=90^{\circ}$ and at $\phi=174^{\circ}$ in spherical target chamber coordinates. The detector uses a PMT140 photomultiplier coupled to a quenched xylene liquid scintillator. We observe increased thermal broadening in going from $1 \mathrm{MJ}$ to $1.3 \mathrm{MJ}$ indicating a temperature increase from $2 \mathrm{keV}$ to $3.6 \mathrm{keV}$. The fit to the NTOF data allows temperature measurements with an error bar of $\pm 0.1 \mathrm{keV}$. Furthermore, the measured yield is in excellent agreement with other detectors that use different methods for determining the neutron yield. On NIF, there are a total of nine NTOF detectors at about 4-22 metre distance from target chamber centre. In addition, Neutron Activation Diagnostics (NADs) and the Magnetic Recoil Spectrometer (MRS) [64] are employed and their locations are listed in Fig. $7 \mathrm{~b}$.

Zirconium, copper, and indium activation foils are used to measure DT and DD yield, $\rho \mathrm{R}$, and $\rho \mathrm{R}$ anisotropies through a suite of NADs. These materials undergo neutron reactions with energy thresholds just below the DT ( $\mathrm{Rr}$ and $\mathrm{Cu}$ ) or DD (In) neutron production energy region of interest. The radioactive decay of the reaction product is then measured to determine the incident primary neutron fluence above the 
Figure 7. (a) Example of neutron time of flight data for the 1 MJ N100929 THD shot and the 1.3 MJ N110212 THD shot. The temporal data (a) clearly show increased thermal broadening for the high-energy implosion. (b) The DT yield data from 11 different NTOF, NAD, and MRS detectors at various lines of sight show excellent agreement among each other with a standard variation of $2.1 \%$.

energy threshold.

The "Well-NAD" diagnostic measures absolute $14.1 \mathrm{MeV}$ DT neutron yield with three $7 \mathrm{~cm}$-diameter zirconium disks of $1.0 \mathrm{~mm}, 3.5 \mathrm{~mm}$, and $8.7 \mathrm{~mm}$ thickness, inserted $4.5 \mathrm{~m}$ from the target chamber centre in a diagnostic well at the $(\theta, \phi)$ coordinates of $(64,241)$. This location is in front of the target chamber first wall but outside the chamber vacuum, which minimizes scatter effects while allowing for easy sample retrieval. The zirconium samples undergo ${ }^{90} \mathrm{Zr}(\mathrm{n}, 2 \mathrm{n})$ reactions with a $12 \mathrm{MeV}$ threshold, producing ${ }^{89} \mathrm{Zr}$ that decays with a 3.27 day half life and emission of $909 \mathrm{keV}$ gamma rays. These gamma rays are measured in a low-background counting facility with highpurity germanium detectors. Corrections to the yield due to attenuation and scatter in the $1 \mathrm{~cm}$ thick aluminum well assembly which holds the sample and the sample itself were calculated to be of order a few percent using MCNP [63]. The absolute DT yield is also measured using copper samples, designated "NAD20," in front of the NTOF20 diagnostics in the neutron alcove at $(116,316)$ at a distance of $\sim 20 \mathrm{~m}$ from the target. The back-to-back $511 \mathrm{keV}$ gamma rays from the $\beta+$ decay of ${ }^{62} \mathrm{Cu}$ are detected in coincident NaI detectors.

We find that the DT yield determined by these diagnostics are in excellent agreement with each other. The error bar for the absolute diagnostics, Well-NAD and MRS are $7 \%$ and $4 \%$, respectively. When comparing the results from all detectors we find for these experiments that the $14.1 \mathrm{MeV}$ DT yield reaches $1.3 \times 10^{14}$ with a standard variation of $2.1 \%$.

\subsection{Fuel assembly}

14.I MeV DT fusion neutrons from the central hot spot plasma loose energy by collisions in the dense fuel shell. Thus, neutrons measured in the energy range between $10 \mathrm{MeV}$ and $12 \mathrm{MeV}$ probe the areal density of layered implosions. The accuracy of these measurements depends strongly on both the areal density, $\rho R$, and the DT yield, and for these experiments we find that at DT yields above $10^{14}$ the down-scattered ratio of $\mathrm{dsr}=N(10-12 \mathrm{MeV}) / N(12-15 \mathrm{MeV})$ can be determined with an error bar of less than $10 \%$. From radiation-hydrodynamic simulations $[29,30]$ the areal density of the fuel is then inferred using $\rho R\left(\mathrm{~g} \mathrm{~cm}^{-2}\right)=21 \times \mathrm{dsr}$.

The Magnetic Recoil Spectrometer (MRS) [64] has been commissioned on NIF to provide high accuracy measurements of the dsr. This diagnostic employs a carbondeuterium (CD) foil (275 $\mu \mathrm{m}$ thick, $13 \mathrm{~cm}^{2}$ area) at a distance of $26 \mathrm{~cm}$ from target 
Figure 8. (a) Example of magnetic recoil spectrometer data for $1.3 \mathrm{MJ}$ THD implosion, shot N110212. The deuteron spectrum provides accurate data on the down scattered ratio. (b) The DT yield data from this shot measured with 8 different NAD detectors at various line of sights and normalized to an isotropic exploding pusher experiment indicate fairly isotropic areal density.

chamber centre and in the direction $\theta=77^{\circ}, \phi=324^{\circ}$. The DT neutrons from the implosion collide with the deuterons in the foil; the forward scattered deuterons are spectrally analyzed by a magnet at a distance of $570 \mathrm{~cm}$ from the foil. The DT neutrons transfer most of their momentum to the deuterons with $n(14.1 \mathrm{MeV})+d \rightarrow$ $n^{\prime}(1.6 \mathrm{MeV})+d(12.5 \mathrm{MeV})$. After passing the magnet, the recoil deuterons are measured with a series of CR-39 detectors and the position allows inferring their energy spectrum.

Figure 8a shows an example of the measured deuteron spectrum from the MRS for a 1.3 MJ THD implosion. While a sufficiently large number of counts for D'T yields above $10^{14}$ results in small error bar for the total counts, the deuteron spectrum from primary and down scattered neutrons is marginally resolved in these data. Future studies will improve the energy resolution by using a medium (125 $\mu \mathrm{m}$ thick, $13 \mathrm{~cm}^{2}$ area) or high resolution ( $50 \mu \mathrm{m}$ thick, $13 \mathrm{~cm}^{2}$ area) $\mathrm{CD}$ foil which will allow $\Delta E / E=0.05$ with the potential to observe non-thermal features in the primary neutron spectrum. In Fig. 8a, a yield of $Y_{D T}=(1.27 \pm 0.1) \times 10^{14}$, a down scattered ratio of $\mathrm{dsr}=(2.8 \pm 0.3) \%$ and an areal density of $\rho R=0.56 \mathrm{~g} \mathrm{~cm}^{-2}$ were determined.

A measurement of the relative neutron yield anisotropies caused by scatter in a spatially-variable areal density of the imploding capsule is provided by the "FlangeNAD" diagnostic system. Neutrons along any particular line of sight that scatter in the dense fuel lose enough energy to drop below the $12 \mathrm{MeV}(\mathrm{n}, 2 \mathrm{n})$ activation threshold of ${ }^{90} \mathrm{Zr}$. By observing relative differences in the activation of $\sim 200 \mathrm{~g}$ zirconium samples placed on the surface of eight to ten ports around the chamber, normalized to an isotropic "exploding pusher" shot, provide a measure of yield anisotropies; deviations as low as $\sim 3 \%$ can be detected. To minimize systematic uncertainties, all samples are measured in the same detector using an automated positioning system. Figure $8 \mathrm{~b}$ shows that the results are consistent with a fairly isotropic distribution within the uncertainties.

The present areal densities of $0.5 \mathrm{~g} \mathrm{~cm}^{-2}$ are higher than achieved on previous laser experiments. For example, experiments at GEKKO XII have reported $0.1 \mathrm{~g} \mathrm{~cm}^{-2}$ [65] and recent experiments at Omega have resulted in $0.3 \mathrm{~g} \mathrm{~cm}^{-2}[66,67,68]$. However, the present values are a factor of three times smaller than predicted by radiationhydrodynamic simulations for fully tuned layered implosions. For this reason, a shock timing campaign is currently underway on NIF, that is designed to tune the timing and strength of the four laser peaks that launch and set the velocity of the four shock waves that travel through the ablator and THD fuel $[39,69]$. 
Figure 9. (a) Gamma-ray history signal is shown from a $1.3 \mathrm{MJ}$ implosion indicating $180 \pm 50 \mathrm{ps}$ burn width, shot N110212. The curves reflect fusion gammas (DT and HT), combined signal from the Thermo Mechanical Package (TMP), and combined signal with the TMP and from ${ }^{12} \mathrm{C}$ in the ablator.

Figure 10. Burn averaged DT and DD neutron yields are shown for cryogenic layered THD implosions and high-pressure D ${ }^{3} \mathrm{He}$ gas-filled symcap implosions. The DT yield follows the expected $T^{4.7}$-scaling with temperature and compare well with twodimensional radiation-hydrodynamic simulations that are multiplied by 0.3 for THD (red area) and 0.5 for DD symcaps (blue area).

\subsection{Burn Duration}

To estimate performance and proximity of an implosion to the ignition regime, we analyze neutron yield, the down scattered ratio, nuclear burn duration and the burnaveraged implosion pressure from x-ray and nuclear diagnostics. Figure 9 shows the experimental traces from the Gamma Ray History (GRH) detector from the $1.3 \mathrm{MJ}$ THD implosion. The GRH detector [70] is located at $\theta=64^{\circ}, \phi=20^{\circ}$ and employs fast photomultipliers with a Mach-Zehnder modulator for optical transmission to measure the Cherenkov emission from high-energy gamma rays produced in the implosion experiment. Commissioning experiments with exploding pusher targets have shown that bang time is measured with an uncertainty of $\pm 30 \mathrm{ps}$ and burn width with an uncertainty of $\pm 15 \mathrm{ps}$.

Four cells are being fielded with two fill gases $\left(\mathrm{CO}_{2}, \mathrm{SF}_{6}\right)$ and pressures to obtain signals for gamma ray photons above $3 \mathrm{MeV}, 5 \mathrm{MeV}$ and $10 \mathrm{MeV}$. Thus, the channels discriminate $\sim 4 \mathrm{MeV} \gamma$-rays from ${ }^{12} \mathrm{C}$ and bremsstrahlung from the hohlraum and target mounting. The $10 \mathrm{MeV}$ channel measures $\gamma$-rays that are produced in the DT fusion reactions, i.e., $D+T={ }^{5} \mathrm{He}^{\star}$ which decays with almost $100 \%$ probability to ${ }^{4} \mathrm{He}(3.5 \mathrm{MeV})+n(14.1 \mathrm{MeV})$ or with a probability of $3 \times 10^{-5}$ to ${ }^{5} \mathrm{He}+\gamma(16.75) \mathrm{MeV}$. For THD implosions, this signal blends with the $H T_{\gamma}$ close to $\sim 20 \mathrm{MeV}$. Advantages of GRH measurements are the facts that the gamma emission is isotropic and insensitive to the areal density.

The three curves in Fig. 9 show a 180 ps long signal from fusion gammas (DT and HT) together with the signal from the Thermo Mechanical Package (TMP), and further combined with the ${ }^{12} \mathrm{C}$ from the ablator. Besides burn duration, these measurements will allow further investigations of DT implosions, where the GRH will be configured to provide an accurate measurement of yield (since the HT gamma signal will be negligible), areal density from the ablator signature, and low-energy neutrons from scattering in the fuel. 


\subsection{Confinement}

Figure 10 shows measured DT and DD neutron yields from cryogenic layered THD and symcap implosions, respectively. The experimental data are compared with twodimensional radiation-hydrodynamic simulations using the code HYDRA [30]. By multiplying the calculated yields with factors of 0.3 for THD and 0.5 for DD, respectively, we obtain a fairly good match between simulations and experiments. The smaller than calculated yields may be explained by the fact that the present simulations do not include surface roughness perturbations from the capsule ablator and the ice, cf. Sec. 3C. Preliminary three-dimensional calculations indicate that including physical surfaces indeed provide a factor of two to three lower yields. Future studies will need to be performed to estimate yields with realistic surfaces, and with the shape and entropy of the present experiments.

In Fig. 10, we observe that the yield from THD implosions follows a simple scaling that is derived from calculations of the total DT yield

$$
Y_{D T}=f_{D} f_{T} n^{2}\left\langle\sigma_{D T} v\right\rangle \times V \times \tau .
$$

Here, $\left\langle\sigma_{D T} v\right\rangle$ is the DT fusion cross section averaged over the Maxwell Boltzmann velocity distribution function, $f_{D}, f_{T}$, and $n$ are the fraction of deuterium and tritium in the plasma and the total number density of deuterium and tritium, respectively. $V$ is the hot spot volume and $\tau$ is the burn duration. The $T^{4.7}$-scaling is primarily a consequence of the cross section scaling with temperature for the present experiments; volume, burn duration and hydrogen isotope ratios are set constant. This result implies no major difference in mix [71] among these THD experiments which is presently being investigated with detailed measurements of the x-ray emission spectra from ablator dopants [72].

The neutron yield and down scattered ratios can be combined into an experimental ignition threshold factor (ITFx) [73]. For an equivalent DT-implosion, the ITFx-value is defined as

$$
\operatorname{ITFx}=\left(\frac{Y_{n}}{3.2 \times 10^{15}}\right)\left(\frac{d s r}{0.07}\right)^{2.3} .
$$

This formalism allows the direct use of accurately measured quantities for estimating the proximity towards the ignition regime for inertial confinement fusion experiments. In this study, we use THD with $f_{D}=0.06$ and $f_{T}=0.72$. To obtain the no alpha self heating equivalent yield, $Y_{n}$, we scale the measured $Y_{D T}$ according to Eq. 8 with $\left(0.5^{2}\right) /(0.06 \times 0.72) \simeq 5.8$ and obtain $I T F x \simeq 0.02$.

THD implosions allow approaching the threshold ITFX values for alpha heating and ignition in controlled well-diagnosed experiments. For example, THD fuel with a deuterium fraction as low as $2 \%$ will allow measurements of threshold conditions at neutron yields of about $Y_{D} T \sim 3.2 \times 10^{15} \times \frac{0.02 \times 0.74}{0.5 \times 0.5}=2 \times 10^{14}$ where alpha heating will not play a role. A series of about 1000 two-dimensional simulations with and without alpha heating has been performed to assess the surrogacy of the THD 
Figure 11. Generalized Lawson confinement parameter, averaged pressure times confinement time, $P_{\tau}$, versus the ion temperature is shown. The figure compares finding from NIF implosions, Omega laser data, and various tokamak results. The data indicate that these first cryogenic layered implosions reach high confinement parameters. For ignition, the implosions will need to be further improved to achieve higher values for $P_{\tau}$ with pressures above 300 Gbar.

platform for determining the threshold for inertial confinement fusion $[14,73]$. The simulations indicate that the higher THD vapor pressures produce different particle densities in the central gas cavity compared with the DT (the fuel mass density has been chosen to be constant). THD implosions with $6 \%$ deuterium at $17.4 \mathrm{~K}$ provide particle densities of $2.9 \times 10^{-4} \mathrm{~mol} / \mathrm{cm}^{3}$, significantly larger than DT implosions at $18 \mathrm{~K}$ with $1.1 \times 10^{-4} \mathrm{~mol} / \mathrm{cm}^{3}$. This effect results in about $10 \%$ lower temperatures in THD implosions compared to DT. Nevertheless, the simulations show that THD implosions with ITFx values of about 1 (1.2) show a $50 \%(90 \%)$ probability for ignition and fusion yield of $20 \mathrm{MJ}$ when fielding the experiment with DT fuel.

With the volume determined from x-ray emission images, the density obtained from x-ray or neutron yield, burn duration from GRH, and temperatures from the NTOF we can determine the pressure and the Lawson confinement parameter. For these experiments, we find that the pressure increases from 9 Gbar at $1 \mathrm{MJ}$ to 30 Gbar for the $1.3 \mathrm{MJ}$ layered THD implosion. Combined with the burn duration we find $1.8 \mathrm{~atm} \times \mathrm{s}$ and $6 \mathrm{~atm} \times \mathrm{s}$.

Figure 11 shows the pressure-time product versus the measured ion temperature for NIF implosion shots. Radiation-hydrodynamic simulations indicate that ignition conditions will be reached at $P_{\tau} \simeq 30$ and no-alpha heating temperatures of $T=4 \mathrm{keV}$. The values achieved in this study are determined from averaged pressure data and well exceed the results quoted from previous fusion experiments [17] including Omega [68] and various tokamaks. The latter include results from DIIID $[74,75]$ and JET $[76,77]$ and have achieved values of order $1 \mathrm{~atm} \times \mathrm{s}$ in both cases.

Future experiments are being planned to further tune the implosions to reach values of about $30 \mathrm{~atm} \times \mathrm{s}$ which are predicted for the ignition regime. The next tuning steps will include improvements in shock timing to lower the entropy and increase the fuel areal density and pressure. Also, the implosion velocity and shape will be further optimized by varying the hohlraum dimensions, by increasing the laser power, and by modifying the capsule ablator.

\section{Conclusions}

We have performed the first non-burning implosion experiments with thermonuclear cryogenic fuel on the National Ignition Facility. These experiments are driven by radiation temperatures of $300 \mathrm{eV}$ produced by $1.3 \mathrm{MJ}$ laser energy delivered by 192 
ultraviolet laser beams. An extensive suite of optical, x-ray, and nuclear diagnostics has demonstrated accurate measurements of important implosion performance parameters. In particular, we find that these first implosions compress to a spherical dense fuel shell of about $0.5 \mathrm{~g} \mathrm{~cm}^{-2}$ that contains a $80 \mu$ m-diameter hot plasma core at temperatures of $3.5 \mathrm{keV}$ which produces a DT neutron yield in excess of $10^{14} 14.1 \mathrm{MeV}$ neutrons. These first layered experiments have shown high areal densities and high Lawson confinement parameters. These implosions provide the experimental platform for tuning mix, velocity, entropy, and shape in preparation for fielding DT implosions with high probability for ignition and thermonuclear burn.

\section{Acknowledgements}

This work performed under the auspices of the U.S. Department of Energy by Lawrence Livermore National Laboratory under Contract DE-AC52-07NA27344. This work was also supported by the U.S. Department of Energy Office of Inertial Confinement Fusion under Cooperative Agreement No. DE-FC52-08NA28302.

[1] Moses E I and Wuest C R 2005 Fusion Sci. Tech. 47314

[2] Haynam C et al. 2007 Appl. Optics 463276

[3]. Glenzer S H et al. 2010 Science 327,1228

[4] Michel P et al. 2010 Phys. Plasmas 17056305

[5] Meezan N B et al. 2010 Phys. Plasmas 17056304

[6] Kline J L et al. 2011 Phys. Rev. Lett. 106, 085003

[7] Glenzer S H et al. 2011 Plyys. Rev. Lett. 106, 085004

[8] Town R P J et al. 2011 Phys. Plasmas 18056302

[9] Lindl J D et al. 1995 Phys. Plasmas 23933

[10] Lindl J D et al. 2004 Phys. Plasmas 11339

[11] Landen O L et al. 2011 Phys. Plasmas 18051002

[12] Haan S W et al. 2011 Phys. Plasmas 18051001

[13] Moses E I 2011, Fusion Sci. Tech. 60, 11

[14] Spears B K et al. 2010 Journal of Physics Conference Series 244022014

[15] Chang Py, Betti R, Spears B K et al. 2010 Phys. Rev. Lett. 104, 135002

[16] Lawson J D 1957, Proceedings of the Physical Society B, 70, p. 6

[17] Betti R et al. 2010 Phys. Plasmas 17, 058102

[18] Zhou C D and R. Betti 2008 Phys. Plasmas 15, 102707, 2009 Phys. Plasmas 16, 079905

[19] Edwards M J et al. 2011 Phys. Plasmas 18051003

[20] Haan S W et al. 1995 Phys. Plasmas, 2, 2480

[21] Atzeni S, Meyer-ter-Vehn J, The Physics of Inertial Fusion (Oxford Univ. Press, New York, 2004)

[22] Kucheyev S O and Hamza A V 2010, J. Appl. Physics 108, 091101

[23] Michel P et al. 2009 Phys. Rev. Lett. 102, 025004

[24] Clark D S, Haan S W, Salmonson J D 2008 Phys. Plasmas, 15, 056305

[25] Robey H 2011 Phys. Plasmas, submitted

[26] Miller J R 1975, Los Alamos Scientific Laboratory Report LA-6245-PR, p. 82; Methods and Apparatusfor Producing Cryogenic Inertially Driven Fusion Targets, U. S. Patent 4,292,340 (Jan. 1987)

[27] Martin A J, Simms R J, and Musinski D L 1988 Sci. Technol. A 6, 1885

[28] Hoffer J K, and Foreman L R 1988 Phys. Rev. Lett. 60, 1310

[29] Zimmerman G B and Kruer W L, Comments Plasma Phys. Control. Fusion 2, 85 (1975). 
[30] Marinak M M et al. 2001 Phys. Plasmas 8, 2275

[31] MacGowan B J et al. 1995, Phys. Plasmas

[32) Glenzer S H et al. 2007 Nature Physics 3, 716

[33] Lefebvre E et al. 1998 Phys. Plasmas 5, 2701

[34] Moody J D et al. 2001 Phys. Rev. Lett. 86, 2810

[35] Kato $Y$ et al. 1984 Phys. Rev. Lett. 53, 1057

[36] Berger R L et al. 1998 Phys. Plasmas 5, 4337

[37] Dewald E L et al. 2011 Phys. Plasmas 18, 092703

[38] Celliers P 2011 Phys. Plasmas., to be submitted

[39] Robey H 2011 Phys. Rev. Lett. , to be submitted

[40] Boehly T R et al. 2011 Phys. Plasmas 18, 092706

[41] Offenberger A A et al. 1982 Phys. Rev. Lett. 49, 371

[42] Paul R P et al. 1984 Phys. Rev. Lett. 53, 1739

(43) Moody J D, Datte P, Krauter K et al. 2010 Rev. Sci. Instrum. 81, 100921

[44] Glenzer S H et al. 1998 Phys. Rev. Lett. 81, 365

[45] Regan S et al. 2010, Phys. Plasmas 17, 020703

[46] Kilkenny J D, Cable M D, Clower C A et al. 1995 Rev. Sci. Instrum. 66, 288

[47] Doeppner $\mathrm{T} 2011$ Phys. Rev. Lett., submitted

[48] Michel P et al. 2009 Pliys. Plasmas 16042702

[49] Michel P et al. 2011 Plyys. Rev. E 83, 046409

[50] Dewald E L et al. 2004 Rev. Sci. Instrum. 75, 3759

[51] Dewald E L, Glenzer S H, Landen O L et al. 2005 Plasma Phys. Cont. Fusion 47, 405

[52] Schneider M B et al. 2010 Rev. Sci. Instrum. 81, 10E538

[53] Meezan NI et al. 2011 Inertial Fusion Science Application Conference, Bordeaux, France.

[54] Dattolo E 2001, et al., Phys. Plasmas 8, 260

[55] Marshak R E 1958, Phys. Fluids 1, 24

[56] Suter L J et al. 1994, Phys. Rev. Lett. 73, 2328

[57] Glenzer S H et al. 1998, Phys. Rev. Lett. 80, 2845

[58] Sigel R et al. 1990, Phys. Rev. Lett. 65, 587

[59] Hauer A A et al. 1995, Phys. Plasmas 2, 2488.

60] Landen O L et al. 1999, Phys. Plasmas 6, 2488

[61] Tumer R E et al. 2000, Phys. Plasmas 7, 333

[62] Kyralla G A, Kline J L, Dixit S et al. 2011 Pliys. Plasmas, 18, 056307

[63] Briesmeister J F1997, MCNP - A General Monte Carlo N-Particle Transport Code, Version 4B, Los Alamos National Laboratory

[64] Frenje J A et al. 2010 Phys. Plasmas 17, 056311

[65] Azechi et al. 1991 Laser and Particle Beams 9, 193-207

[66] Betti R et al. 2006 Plasma Phys. Control. Fusion 48 B153B163

67) Goncharov et al. 2010 Physics Review Letters 104, 165001

[68] Sangster et al. 2008 Physics Review Letters 100, 185006

[69] Mackimnon A J et al. 2011 Physics Review Letters submitted

[70] Hermann H W, Hoffman N, Wilson D C et al. 2010 Rev. Sci. Instrum. 81, 10D333

[71] Hammel B A et al. 2010, Phys. Plasmas 18, 056310

[72] Regan S 2011 Phys. Rev. Lett. , submitted

[73] Spears B K et al, Phys. Plasmas, to be submitted

[74] Lazarus E A, Navratil G A, Greenfield C M et al. 1996, Phys. Rev. Lett. 77, 2714

[75] Lazarus E A, Navratil G A, Greenfield C M et al. 1997, Nuclear Fusion 37, 7

[76] KeilhackerM et al. 1999 Plasma Phys. Control. Fusion 41 B1B23

[77] Keilhacker M, Gibson A, Gormezano C et al. 1999 Nucl Fusion 39, 209 


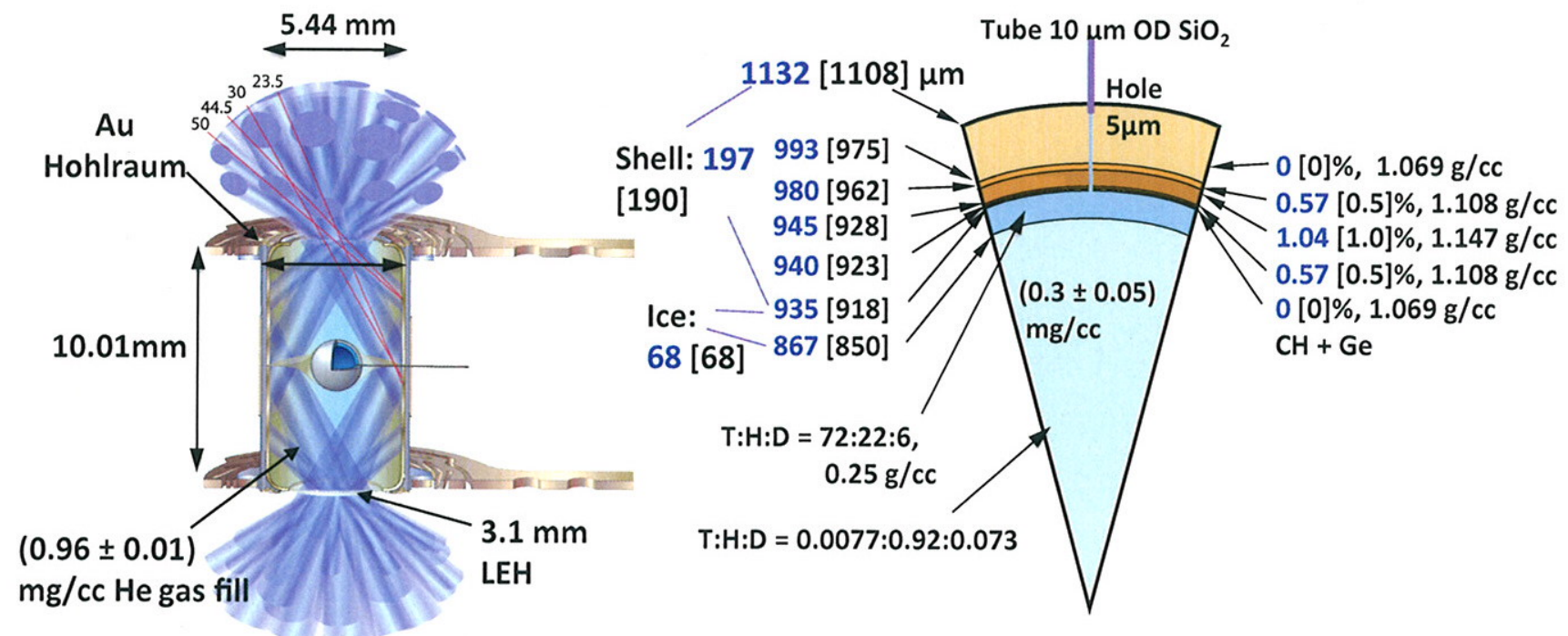

Figure 1, Glenzer et al. 

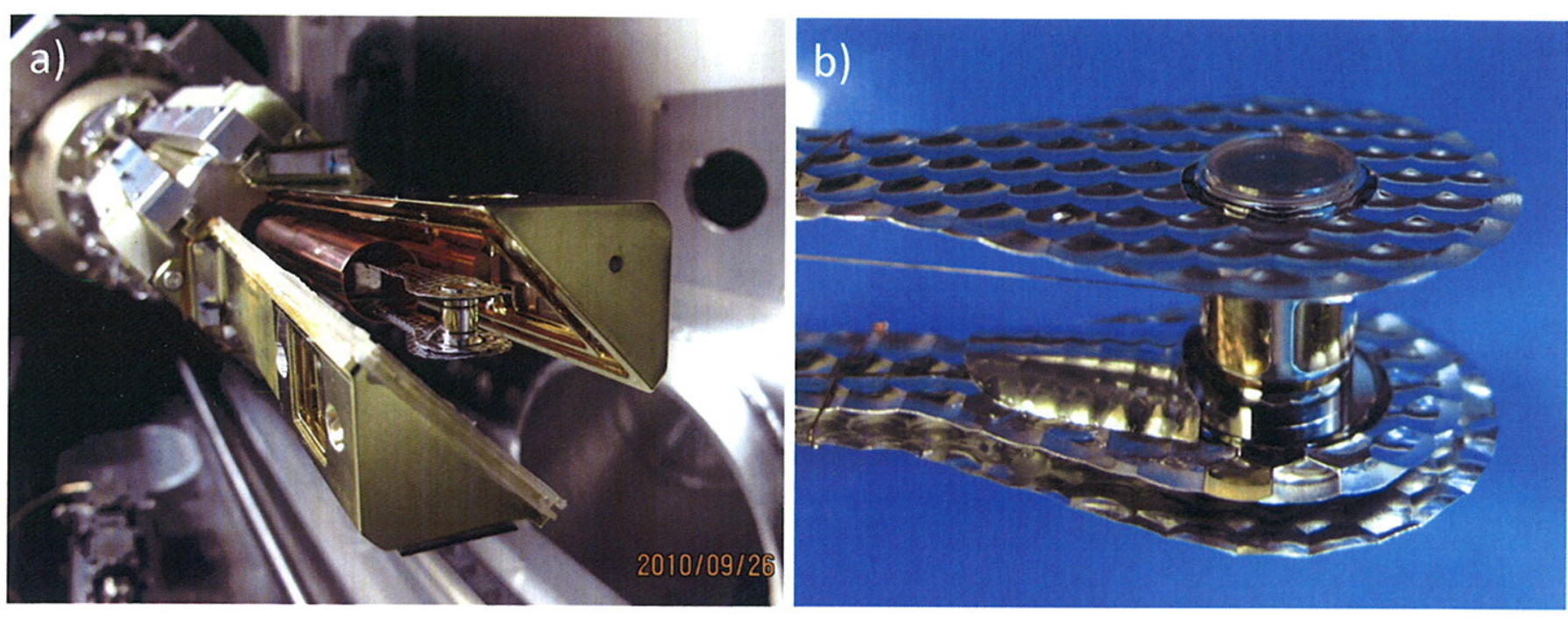

Figure 2, Glenzer et al. 


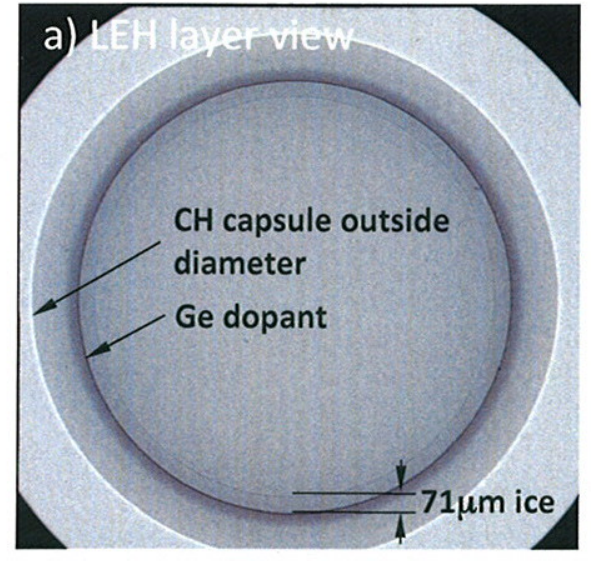

d) meniscug height at triple point

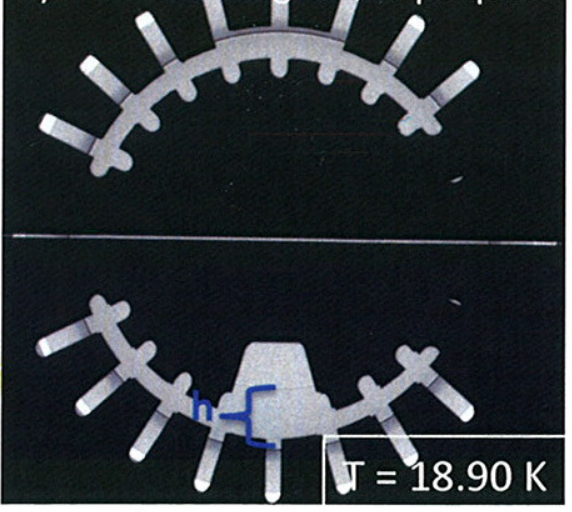

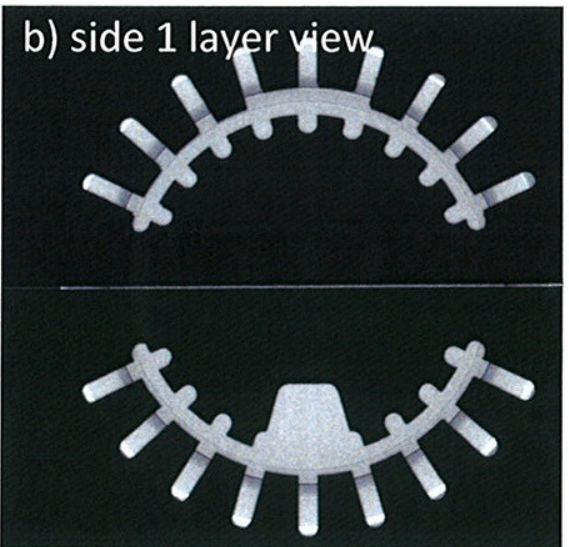

e) example of modal data

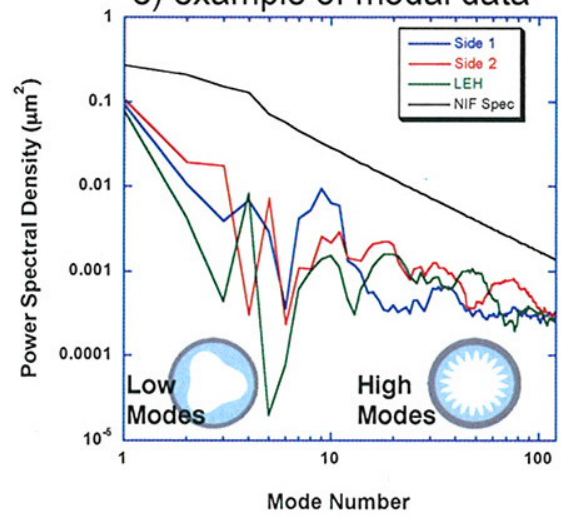

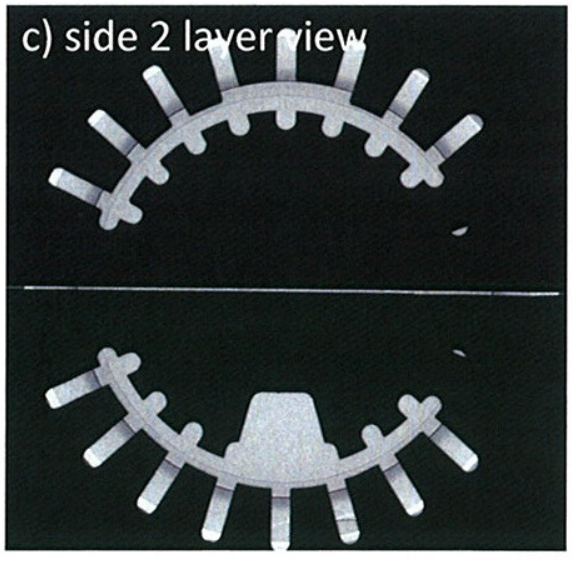

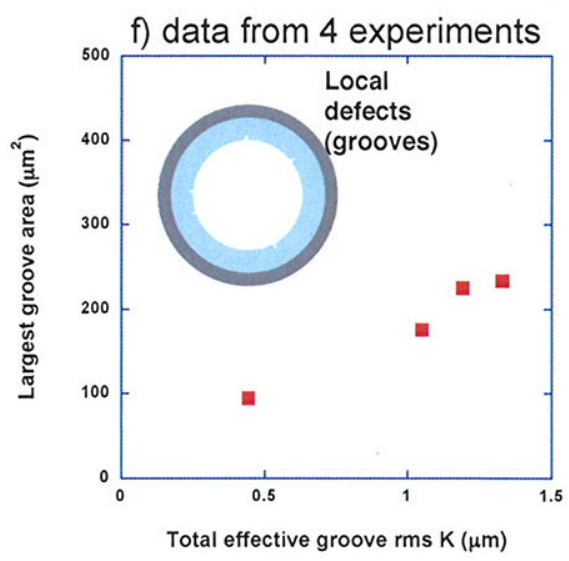

Figure 3, Glenzer et al. 

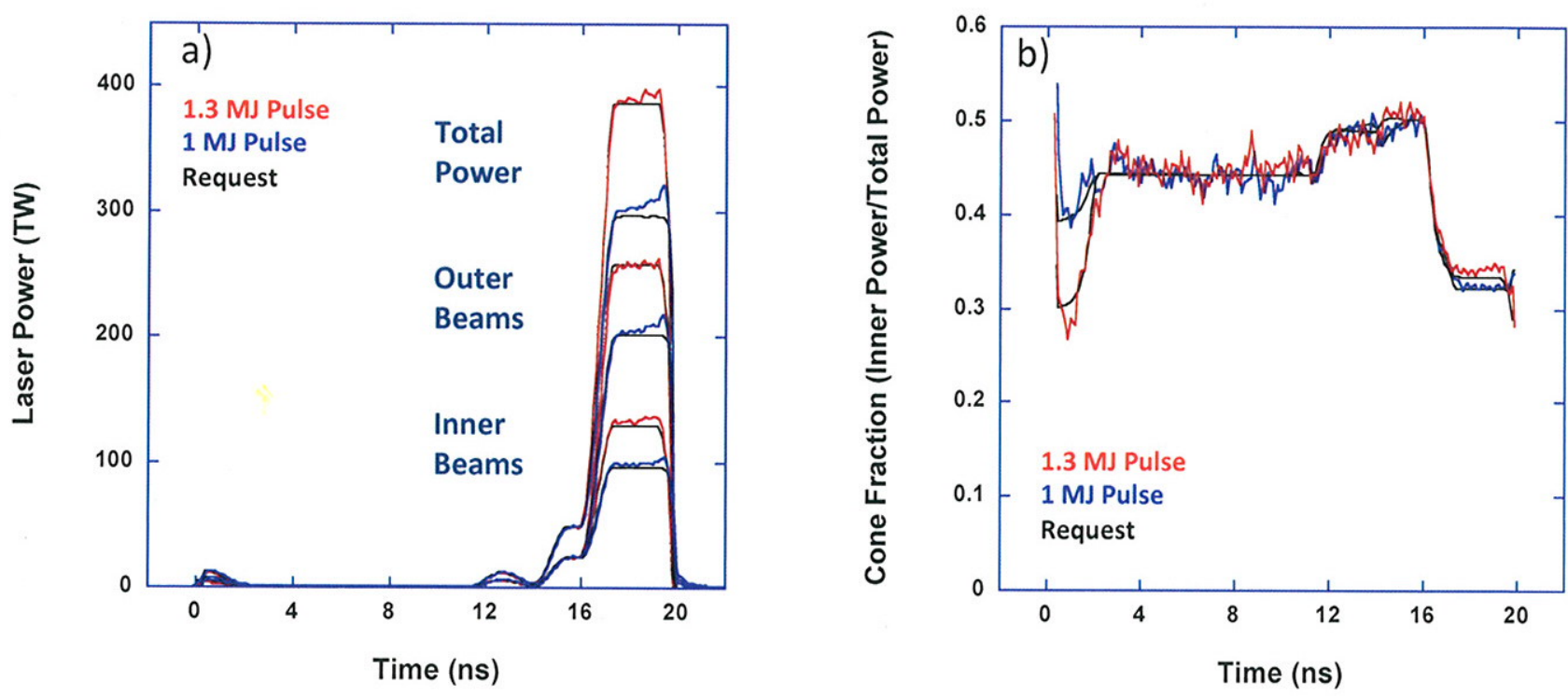

Figure 4, Glenzer et al. 

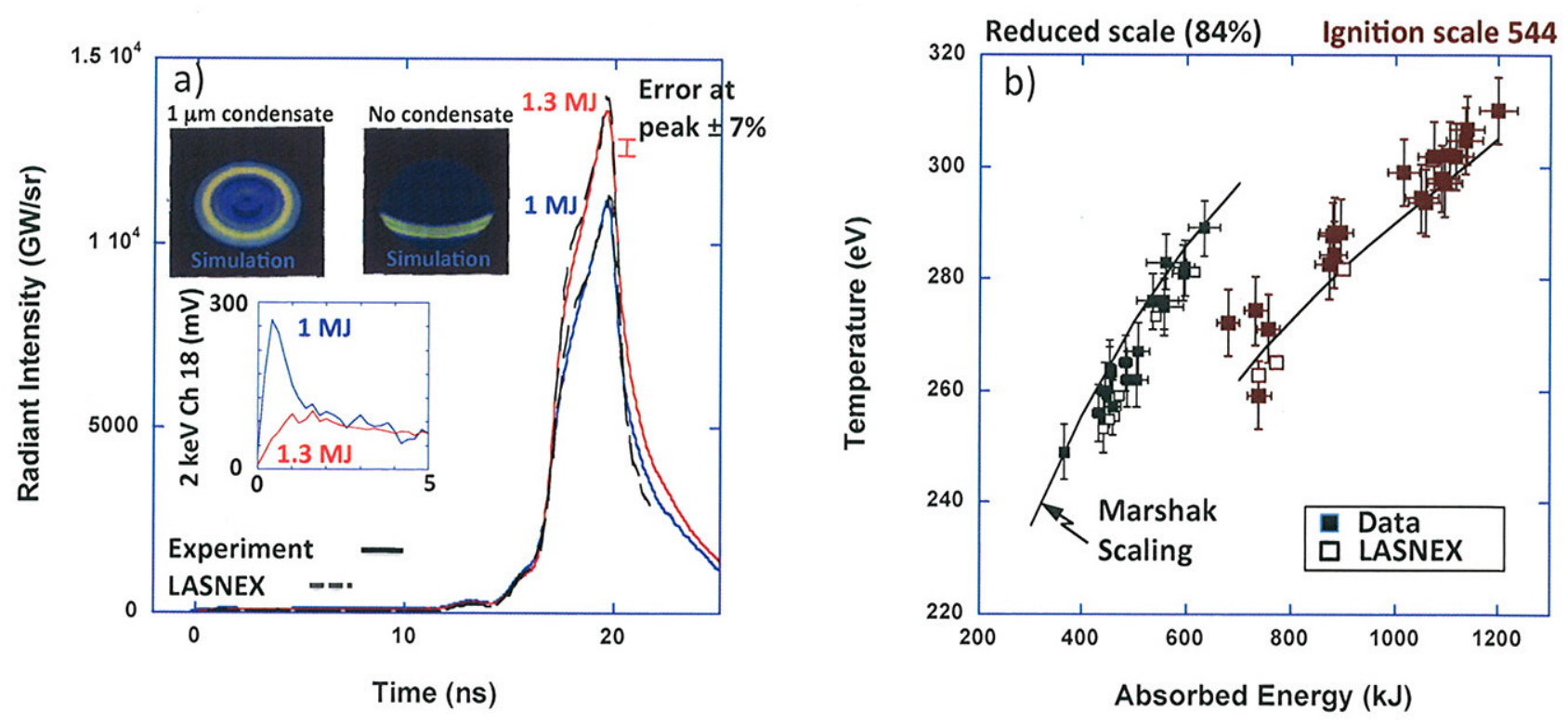

Figure 5, Glenzer et al. 

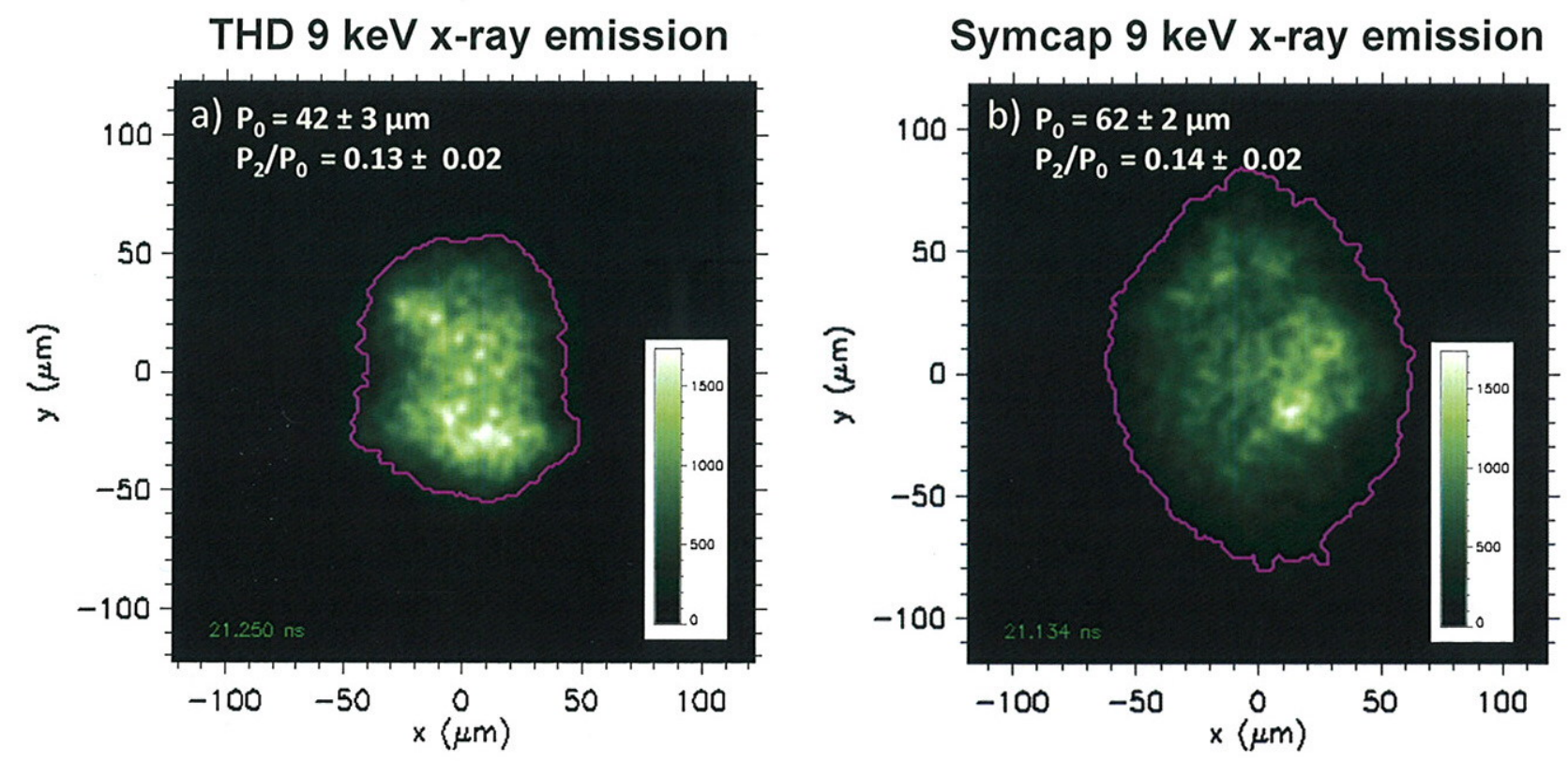

Figure 6, Glenzer et al. 


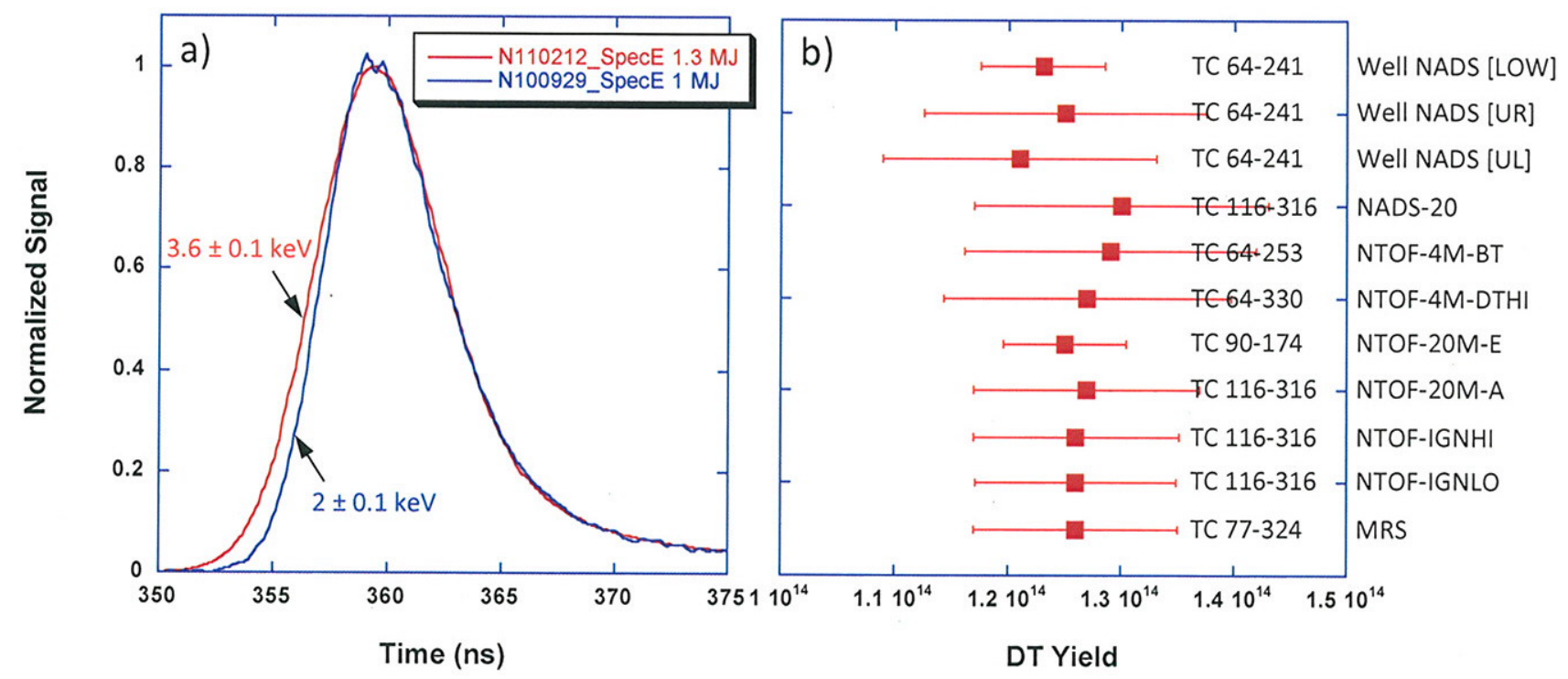

Figure 7, Glenzer et al. 

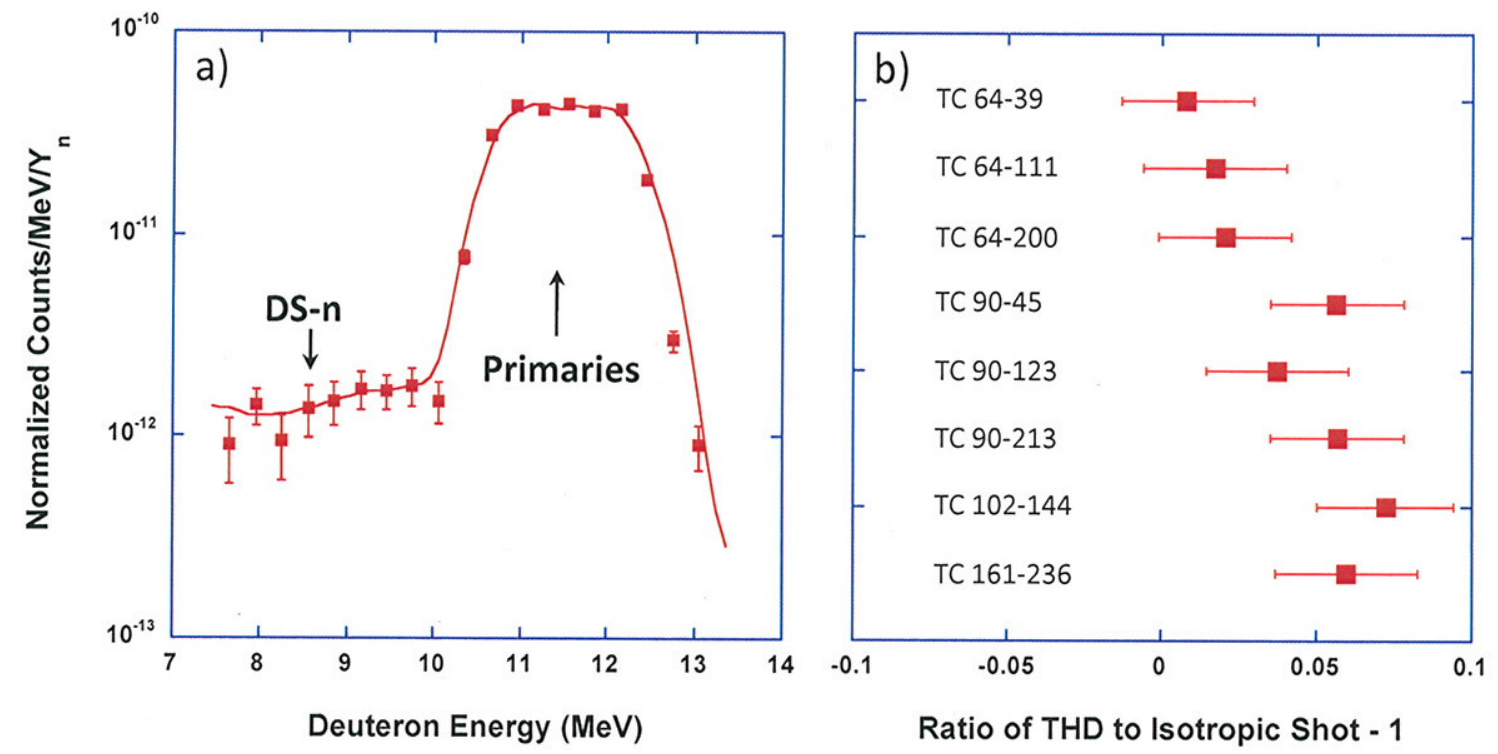

Figure 8, Glenzer et al. 


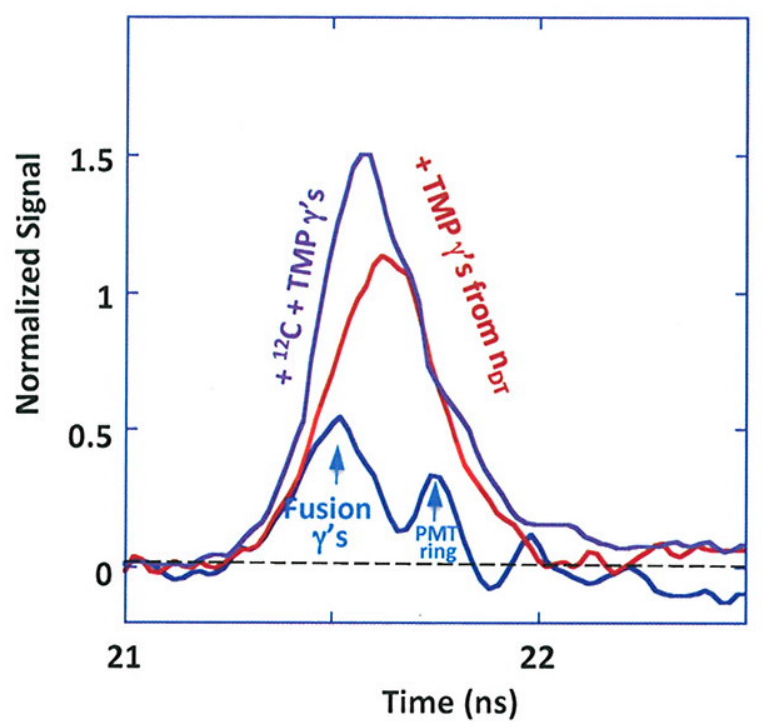

Figure 9, Glenzer et al. 


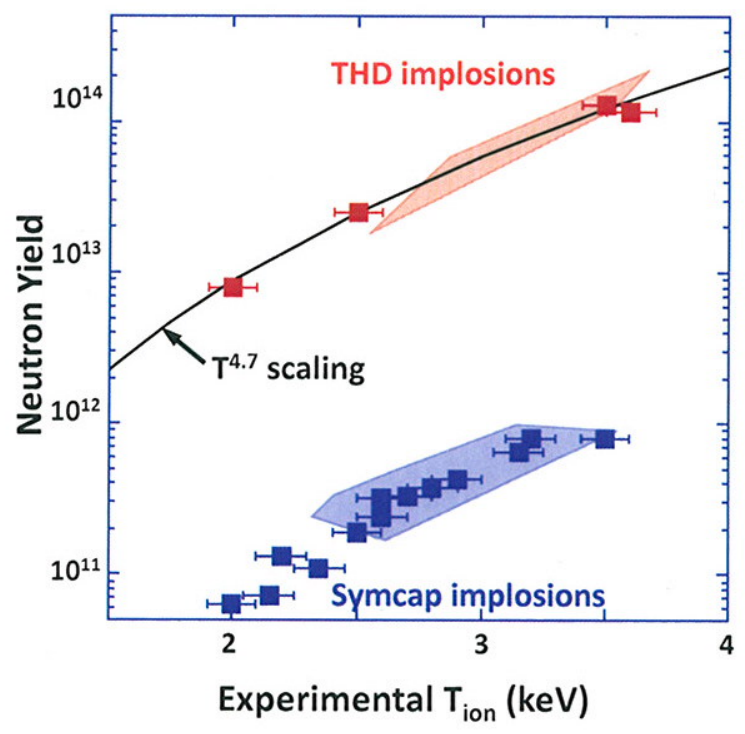

Figure 10, Glenzer et al. 


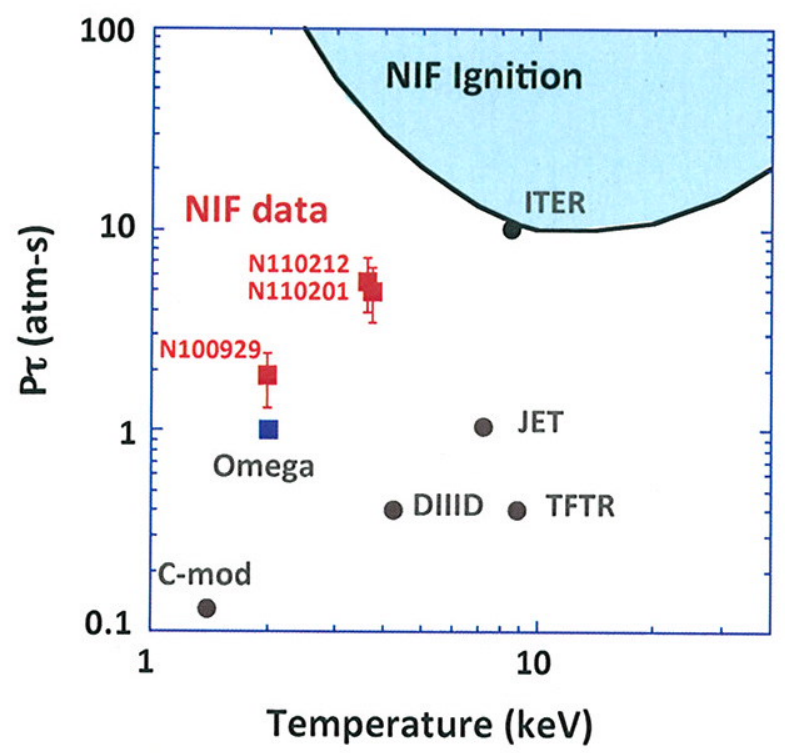

Figure 11, Glenzer et al. 